\title{
Glutathione redox state, glutathione peroxidase activity and selenium concentration in periparturient dairy cows, and their relation with negative energy balance
}

\author{
K. Mikulková1, J. Illek and R. Kadek \\ University of Veterinary and Pharmaceutical Sciences Brno, Faculty of Veterinary Medicine, Large Animal Clinical Laboratory, \\ Brno 612 42, Czech Republic
}

KEY WORDS: antioxidants, dairy cows, energy deficiency, glutathione, oxidative stress, periparturient period

Received: $\quad 17$ April 2019

Revised: 25 November 2019

Accepted: 18 February 2020
${ }^{1}$ Corresponding author:

e-mail: mikulkovak@vfu.cz

\begin{abstract}
The aim of the study was to evaluate glutathione redox state, glutathione peroxidase (GPx) activity, and selenium (Se), non-esterified fatty acids (NEFA) and $\beta$-hydroxybutyrate (BHB) concentrations in 15 Holstein periparturient dairy cows and to monitor the effect of negative energy balance (NEB) on the level of oxidative processes ongoing in dairy cows in postpartum period. The body condition score (BCS) was recorded and blood samples were collected 4 times during periparturient period. A significantly increased NEFA concentration was recorded on calving day $(P<0.05)$ and 7 days post partum (p.p.; $P<0.01$ ) compared to 7 days ante partum (a.p.). The reduced glutathione (GSH) concentration was significantly decreased on calving day and 7 days p.p. $(P<0.05)$ as compared to 7 days a.p. The oxidized glutathione (GSSG) concentration was significantly higher 7 days p.p. as compared to calving day $(P<0.01)$ and 14 days p.p. $(P<0.05)$. Between the GSSG concentration and the GSH/GSSG ratio was found a significantly negative $(r=-0.84 ; P<0.001)$ correlation. The significant decrease in GPx activity was found 14 days p.p. as compared to 7 days a.p. $(P<0.05)$. The BCS value was significantly positively correlated $(r=0.44 ; P<0.05)$ with GSSG concentration. The results of the study indicate significant changes of antioxidant/oxidant markers and also confirm that in the postpartum period oxidative stress occurs in dairy cows. It also seems that BCS correlates with these indicators and may influence the level of oxidative processes in cows during the periparturient period.
\end{abstract}

\section{Introduction}

Negative energy balance (NEB) occurs in dairy cows during the periparturient period and is induced by increased energy and nutrients requirements. This higher energy and nutrient demand is important for fetal development and for postpartum milk production. There is also a significant decrease in intake of dry matter (Sordillo and Aitken, 2009; Esposito et al., 2014). NEB is associated with metabolic disorders, increased inflammation, immunosuppression and oxidative stress (Mayasari et al., 2016). Metabolic changes in the transition period are accompanied by increased production of reactive oxygen species (ROS) as well as reactive nitrogen species (RNS) followed by lipid peroxidation and cellular damage to tissues. Carbohydrate insufficiency in dairy cows with NEB leads to lipid mobilization and increased production of non-esterified fatty acids (NEFA) and ketone bodies in the liver (Sordillo, 2005; Spears and Weiss, 2008; Esposito et al., 2014). 
Glutathione is a very important component of the antioxidant defense system because of its ability to protect cells from oxidative stress. One method of protecting cells is by using glutathionedependent enzymes such as glutathione peroxidase (GPx) (Meister, 1983; Enkvetchakul et al., 1995). During reduction of $\mathrm{H}_{2} \mathrm{O}_{2}$ to $\mathrm{H}_{2} \mathrm{O}$, which is catalyzed by GPx, reduced glutathione (GSH) is transformed into oxidized glutathione (GSSG) and serves as an electron donor. GSSG is converted back to GSH by glutathione reductase using reduced nicotinamide adenine dinucleotide phosphate (NADPH). Under physiological conditions, the reduced form is present in a higher concentration. Oxidative stress can be the reason of the increase in GSSG concentration, or of the decrease in the GSH/GSSG ratio (Meister and Anderson, 1983; Cao et al., 2013). Thus, significant changes in the intracellular GSH and GSSG concentrations usually indicate oxidative stress and the GSH/GSSG ratio is considered to be one of the best indicators of oxidative stress (Tarin, 1996; Tarin et al., 1998; Avanzo et al., 2001; Kaneko et al., 2001).

Along with the concentration of reduced and oxidized form of glutathione and the ratio of GSH/ GSSG, determining GPx activity is considered to be one of the main indicators of oxidative stress (Pilarczyk et al., 2012; Cao et al., 2013). GPx, as a selenium-dependent antioxidant enzyme, is also used in indirect determination of selenium (Se) status and indicates long-term Se supplementation (Pavlata et al., 2000). Se status in organisms, especially in the periparturient period, is very important for health, immunity and growth. A deficiency of this antioxidant can contribute to increased incidence of oxidative stress and the associated increased incidence of mastitis (Gong and Xiao, 2016).

Based on the above findings, we decided to monitor the effect of NEB on the level of oxidative stress in dairy cows. The NEB that occurs in dairy cows after parturition was monitored using BCS value and the determination of the NEFA concentration as an indicator of the energy balance in dairy cows (Omur et al., 2016). Cows with a higher body condition score (BCS) value before parturition are predisposed to lose more body condition in the periparturient period and are characterized by a significantly higher NEFA concentration around parturition due to the already mentioned ongoing lipid mobilization (Omur et al., 2016). Along with these changes, we also expected an increase in oxidative stress indicators and a decrease in antioxidants in postpartum period in dairy cows. According to our hypothesis, the changes in BCS during periparturient period in dairy cows should be proportional to the level of ongoing oxidative processes after parturition. The aim of the study was to evaluate glutathione redox state, GPx activity and Se concentration in dairy cows during periparturient period. NEFA and $\beta$-hydroxybutyrate (BHB) concentrations were also measured.

\section{Material and methods}

Experiments were approved by the Czech Animal Experiments Committee (21599/2014-MZE-17214; PP 11-2017).

\section{Animals and diets}

The study was carried out using 15 Holstein dairy cows at a farm located in the village of Uherčice (Břeclav, South Moravia, Czech Republic). Cows selected for testing had no complications of the diseases, the BCS was 3.50 and all of the cows were multiparous, specifically cows ranging from the second to the fourth lactation were included in the experiment. None of the cows were treated for diseases during the experimental period, and none of them had calving complications (only single pregnancy). There were no instances of death or culling. The mean milk production was 103371 per last lactation (it ranged from 6287 to 12722 1). The cows were fed a total mixed ration (TMR) according to the antepartum and postpartum period (formulated feed amounts and nutritional values are given in Table 1).

\section{Study design}

Blood samples were collected 4 times during the periparturient period according to different ante partum (a.p.) and post partum (p.p.) stages: 7 days a.p. $(\mathrm{n}=15)$, calving day $(\mathrm{n}=15), 7$ days p.p. $(n=15)$ and 14 days p.p. $(n=15)$. Indicators of antioxidant status and metabolites concentrations were determined in a total of 60 blood samples. The BCS was recorded at every single blood collection of the cows. At 7 days a.p. mean values of BCS were $3.50 \pm 0.25$, on calving day $3.50 \pm 0.27$, at 7 days p.p. $3.25 \pm 0.40$ and at 14 days p.p. $3.00 \pm 0.35$. The average milk yield was 49.71 in the first month of lactation.

\section{Sampling and analysis}

NEFA and BHB concentrations. Blood samples were collected from the vena coccygea mediana into Hemos sampling tubes without anticoagulant. For serum samples, blood was allowed to coagulate at room temperature and centrifuged (3000 rpm) for $10 \mathrm{~min}$. After blood collection, samples were immediately analyzed or stored at $-70^{\circ} \mathrm{C}$. 
Table 1. Total mixed ration composition

\begin{tabular}{|c|c|c|}
\hline Indices & Ante partum & Post partum \\
\hline \multicolumn{3}{|l|}{ Ingredients, kg } \\
\hline alfalfa hay & 2 & 1 \\
\hline barley straw & 2.2 & 0 \\
\hline concentrate (DOVP) ${ }^{1}$ & 0 & 6 \\
\hline concentrate (DOVP - a.p.) $)^{2}$ & 2.8 & 0 \\
\hline post-extraction rapeseed meal & 0.8 & 0 \\
\hline palmitate & 0 & 0.15 \\
\hline MP iont ${ }^{3}$ & 0.5 & 0 \\
\hline high moisture maize & 0 & 3 \\
\hline brewers grains & 0 & 4 \\
\hline alfalfa haylage & 0 & 6 \\
\hline maize silage & 15 & 19 \\
\hline total amount & 23.30 & 39.15 \\
\hline $\mathrm{DM}^{4}, \mathrm{~kg}$ & 12.9 & 19.5 \\
\hline $\mathrm{DM}, \%$ & 55.4 & 49.8 \\
\hline \multicolumn{3}{|l|}{ Nutrient content } \\
\hline crude protein, \% of DM & 15.0 & 16.8 \\
\hline crude fibre, $\%$ of DM & 21.1 & 15.5 \\
\hline crude fat, $\%$ of DM & 3.1 & 4.6 \\
\hline $\mathrm{NEL}^{5}, \mathrm{MJ}$ of DM & 5.63 & 6.67 \\
\hline $\mathrm{Ca}, \%$ of DM & 0.88 & 0.69 \\
\hline $\mathrm{P}, \%$ of $\mathrm{DM}$ & 0.48 & 0.41 \\
\hline $\mathrm{Na}, \%$ of $\mathrm{DM}$ & 0.24 & 0.40 \\
\hline $\mathrm{K}, \%$ of DM & 1.33 & 1.21 \\
\hline $\mathrm{Mg}, \%$ of $\mathrm{DM}$ & 0.60 & 0.27 \\
\hline $\mathrm{Cl}, \%$ of $\mathrm{DM}$ & 1.12 & 0.38 \\
\hline $\mathrm{S}, \%$ of DM & 0.38 & 0.28 \\
\hline Zn, mg of DM & 68 & 114 \\
\hline Mn, mg of DM & 57 & 139 \\
\hline $\mathrm{Cu}, \mathrm{mg}$ of DM & 31 & 33 \\
\hline Co, mg of DM & 0.32 & 0.73 \\
\hline I, mg of DM & 1.14 & 0.82 \\
\hline Se, mg of DM & 1.09 & 0.49 \\
\hline vitamin A, IU & 216 & 255 \\
\hline vitamin D, IU & 49 & 37 \\
\hline vitamin $\mathrm{E}, \mathrm{mg}$ & 17600 & 884 \\
\hline \multicolumn{3}{|c|}{$\begin{array}{l}{ }^{1} \mathrm{DOVP} \text { - complementary feed for lactating dairy cows; }{ }^{2} \mathrm{DOVP} \text {-a.p. } \\
\text { complementary feed for dairy cows ante partum; }{ }^{3} \mathrm{MP} \text { iont - mixture of } \\
\text { anions }\left(\mathrm{CaCl}_{2}, \mathrm{MgSO}_{4}\right) \text {, mineral supplements and protein concentrate } \\
\text { (to prevent postpartum hypocalcaemia); }{ }^{4} \mathrm{DM} \text { - dry matter; }{ }^{5} \mathrm{NEL} \text { - net } \\
\text { energy lactation }\end{array}$} \\
\hline
\end{tabular}

Serum NEFA and BHB concentrations were measured with standardized kits (Randox Laboratories Ltd., Crumlin, UK) using an automatic biochemical analyzer Konelab 20XT (Thermo Fisher Scientific, Vantaa, Finland).

Glutathione redox state. Blood samples were collected from the vena coccygea mediana into Hemos sampling tubes with heparin anticoagulant. For analysis of GSH concentration $50 \mu \mathrm{l}$ of whole blood was frozen and stored at $-70{ }^{\circ} \mathrm{C}$ before determination, and for analysis of GSSG concentration $100 \mu \mathrm{l}$ of whole blood was added to $10 \mu \mathrm{l}$ of thiol-scavenging reagent 1-methyl-2-vinylpyridinium trifluoromethanesulfonate (M2VP) and was then frozen and stored at $-70{ }^{\circ} \mathrm{C}$ before determination. Reduced and oxidized glutathione concentrations were measured with a BIOXYTECH GSH/GSSG412 kit (OxisResearch, Portland, OR, USA) using a colorimetric enzymatic method developed by Tietze (1969). This method is based on the change in colour development during the reaction. Reaction rate is proportional to the GSH and GSSG concentrations. 5,5'-dithiobis-2-nitrobenzoic acid (DTNB) reacts with GSH/GSSG to form a spectrophotometrically detectable product at $412 \mathrm{~nm}$. An Evolution 160 spectrophotometer (Thermo Fisher Scientific, Waltham, MA, USA) was used to measure GSH and GSSG concentrations.

GPx activity and Se concentration. Blood samples were collected from the vena coccygea mediana into Hemos sampling tubes with heparin. After blood collection, samples were immediately analyzed or stored at $-70{ }^{\circ} \mathrm{C}$. GPx activity in whole blood was measured by a RANSEL kit (Randox Laboratories Ltd., Crumlin, UK) using a UV method based on that of Paglia and Valentine (1967). This method is based on measuring the decrease in absorbance at $340 \mathrm{~nm}$ due to NADPH oxidation by the reaction with glutathione reductase (GR). For determination of GPx the automatic biochemical analyzer Konelab 20XT (Thermo Fisher Scientific, Vantaa, Finland) was used. The Se concentration in whole blood was analyzed using hydride generation atomic absorption spectrometry - HG AAS (SOLAAR, Thermo Fisher Scientific, Waltham, MA, USA). The samples were prepared by mineralization with $\mathrm{HNO}_{3}$ and $\mathrm{H}_{2} \mathrm{O}_{2}$ using microwave digestion system ETHOS TOUCH CONTROL (Milestone, Sorisole, Italy) followed by evaporation.

\section{Statistical analysis}

The obtained results were tested for the homogeneity of variances (Hartley-Cochran-Bartlett test) and the normality of distribution (Shapiro-Wilk test). The data were analyzed statistically by oneway analysis of variance (ANOVA) followed by the Fisher LSD post-hoc test. All results were expressed as mean value $(\mathrm{x})$ and standard error of means (SEM). The relationship between the glutathione concentrations in whole blood and BCS values were evaluated by the correlation coefficient and the significance of correlation using linear regression analysis. 


\section{Results}

\section{Negative energy balance - BCS values, NEFA and BHB concentrations}

A significantly increased NEFA concentration was recorded on calving day $(P<0.05)$ and 7 days p.p. $(P<0.01)$ compared to 7 days a.p. (Table 2$)$. The highest mean BHB concentration was found 7 days p.p. The difference in the increase was not, however, significant $(P>0.05)$. Between the BCS value and NEFA concentration no significant correlation was found $(P>0.05)$. The differences in BCS value and NEFA concentration in individual groups are shown in Figure 1.

Table 2. Non-esterified fatty acids (NEFA) and $\beta$-hydroxybutyrate (BHB) concentrations in dairy cows from 7 days ante partum (a.p.) to 14 days post partum (p.p.)

\begin{tabular}{llll}
\hline $\begin{array}{l}\text { Peripartum } \\
\text { stages }\end{array}$ & $\mathrm{NEFA}$ & $\begin{array}{l}\mathrm{BHB}, \\
\mathrm{mmol} / \mathrm{l}\end{array}$ \\
\hline 7 days a.p. & $\mathrm{x}$ & $0.27^{\mathrm{a}, \mathrm{A}}$ & 0.57 \\
& SEM & 0.06 & 0.04 \\
calving day & $\mathrm{x}$ & $0.50^{\mathrm{a}}$ & 0.55 \\
& $\mathrm{SEM}$ & 0.10 & 0.05 \\
7 days p.p. & $\mathrm{x}$ & $0.56^{\mathrm{A}}$ & 0.64 \\
& SEM & 0.08 & 0.06 \\
14 days p.p. & $\mathrm{x}$ & 0.38 & 0.59 \\
& SEM & 0.06 & 0.05 \\
\hline
\end{tabular}

$\mathrm{x}$ - mean value; SEM - standard error of means; significant differences between groups are indicated by using the same indices in a column: $a-P<0.05, A-P<0.01$

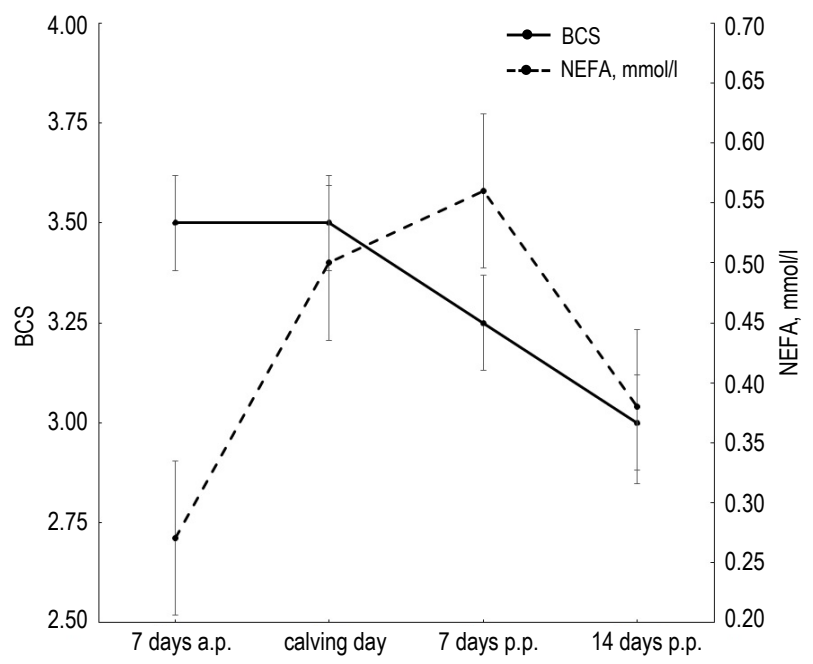

Figure 1. Mean body condition score (BCS) value and serum nonesterified fatty acid (NEFA) concentration in dairy cows during the negative energy balance (from 7 days ante partum (a.p.) to 14 days post partum (p.p.))

\section{Glutathione redox state}

The results of reduced and oxidized glutathione are presented in Table 3. The lowest mean GSH concentration was recorded on calving day and the
Table 3. Glutathione redox state in dairy cows from 7 days ante partum (a.p.) to 14 days post partum (p.p.)

\begin{tabular}{llclc}
\hline $\begin{array}{l}\text { Peripartum } \\
\text { stages }\end{array}$ & & $\begin{array}{l}\text { GSH, } \\
\mu \mathrm{mol} / /\end{array}$ & $\begin{array}{l}\text { GSSG, } \\
\mu \mathrm{mol} / /\end{array}$ & $\begin{array}{l}\text { GSH/GSSG } \\
\text { ratio }\end{array}$ \\
\hline 7 days a.p. & $\mathrm{x}$ & $1005^{\mathrm{a}, \mathrm{B}}$ & 5.18 & 246 \\
& SEM & 37.7 & 0.58 & 39.5 \\
calving day & $\mathrm{x}$ & $867^{\mathrm{a}}$ & $4.25^{\mathrm{A}}$ & 248 \\
& SEM & 53.3 & 0.55 & 34.1 \\
7 days p.p. & $\mathrm{x}$ & $881^{\mathrm{B}}$ & $6.61^{\mathrm{a}, \mathrm{A}}$ & 171 \\
& SEM & 38.8 & 0.61 & 44.0 \\
14 days p.p. & $\mathrm{x}$ & 915 & $4.74^{\mathrm{a}}$ & 256 \\
& SEM & 58.7 & 0.79 & 43.8 \\
\hline
\end{tabular}

$\mathrm{x}$ - mean value; SEM - standard error of means; significant differences between groups are indicated by using the same indices in a column: $a, B-P<0.05, A-P<0.01 ; G S H$ - reduced glutathione; GSSG - oxidized glutathione; GSH/GSSG - glutathione ratio

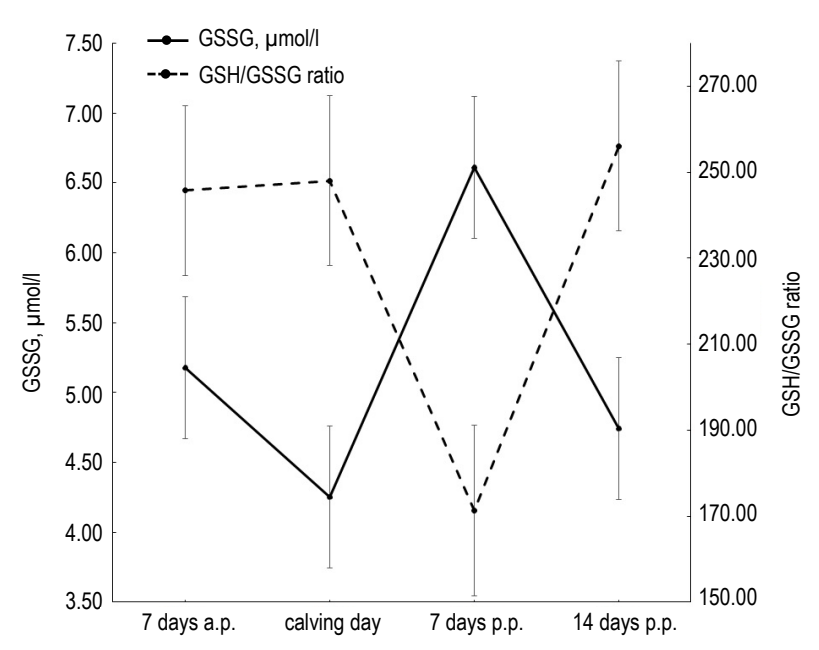

Figure 2. Mean whole blood oxidized glutathione (GSSG) concentration and GSH/GSSG ratio value in dairy cows during the negative energy balance (from 7 days ante partum (a.p.) to 14 days post partum (р.p.))

difference in the decreases was significant as compared to 7 days a.p. $(P<0.05)$. The GSH concentration was also significantly decreased 7 days p.p. as compared to 7 days a.p. $(P<0.05)$. In contrast to GSH concentration, the mean GSSG concentration in the study was significantly higher 7 days p.p. as compared to calving day $(P<0.01)$ and 14 days p.p. $(P<0.05)$. The differences in GSSG concentration and GSH/ GSSG ratio in individual groups are shown in Figure 2. The differences in GSH/GSSG ratio were not, however, significant $(P>0.05)$. A significantly negative $(\mathrm{r}=-0.84 ; P<0.001)$ correlation was found between the GSSG concentration and the GSH/GSSG ratio (Figure 3). The BCS value was significantly positively correlated $(\mathrm{r}=0.44 ; P<0.05)$ to GSSG concentration. Between the BCS value and GSH/GSSG ratio a negative correlation was found $(\mathrm{r}=-0.30)$ but was not, however, significant 


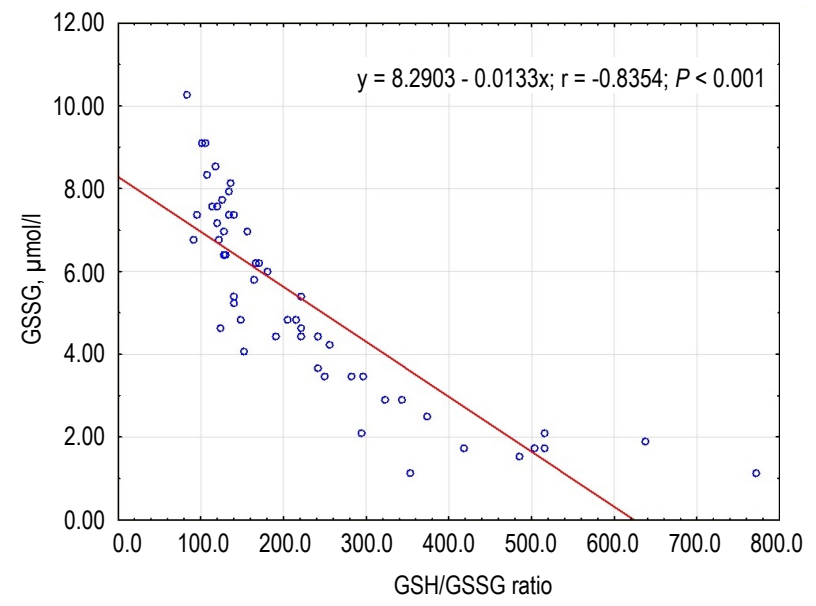

Figure 3. Correlation between whole blood oxidized glutathione (GSSG) concentration and GSH/GSSG ratio value in dairy cows during the negative energy balance

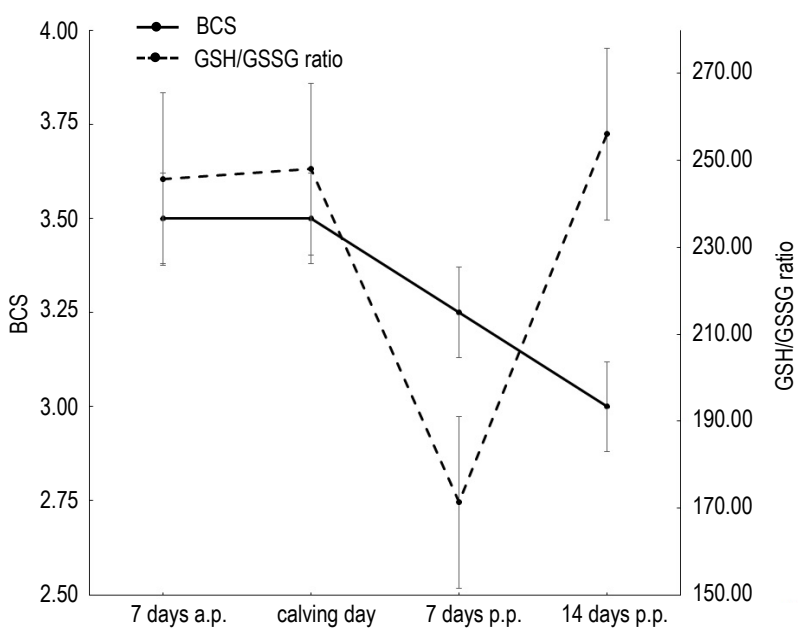

Figure 4. Mean body condition score (BCS) and whole blood GSH/ GSSG ratio values in dairy cows during the negative energy balance (from 7 days ante partum (a.p.) to 14 days post partum (p.p.))

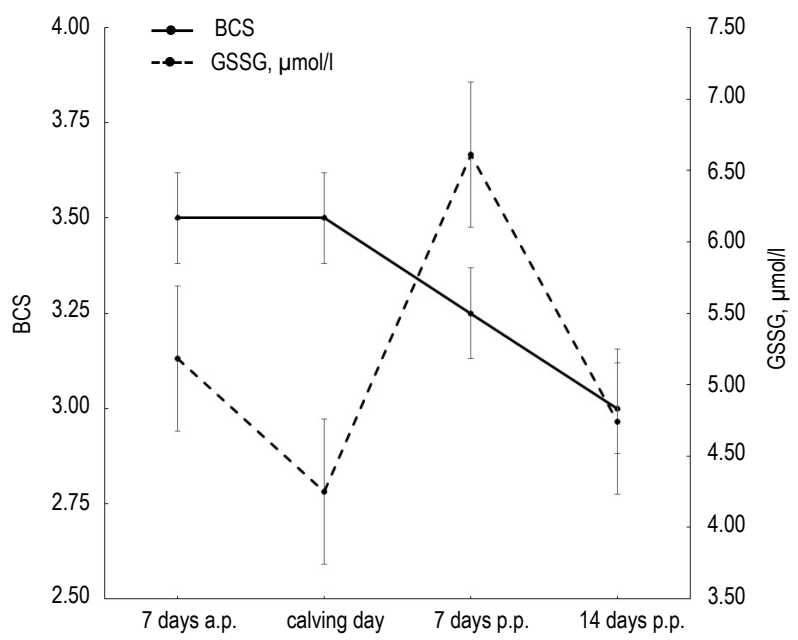

Figure 5. Mean body condition score (BCS) value and whole blood oxidized glutathione (GSSG) concentration in dairy cows during the negative energy balance (from 7 days ante partum (a.p.) to 14 days post partum (p.p.))
$(P>0.05)$. The differences in BCS value and GSH/ GSSG ratio and GSSG concentration in individual groups are shown in Figure 4 and 5, respecively.

\section{GPx activity and selenium concentration}

The results of GPx activity and Se concentration are presented in Table 4. The significant difference in GPx activity was found between 14 days p.p. and 7 days p.p. $(P<0.05)$. The lowest Se concentration was recorded at 7 days a.p., but it was not significant compared to the other blood samplings. No significant change $(P>0.05)$ in Se concentration between individual groups was recorded.

Table 4. Glutathione peroxidase activity (GPx) and selenium concentration (Se) in dairy cows from 7 days ante partum (a.p.) to 14 days post partum (p.p.)

\begin{tabular}{llcc}
\hline $\begin{array}{l}\text { Peripartum } \\
\text { stages }\end{array}$ & $\begin{array}{l}\text { GPx, } \\
\mu k a t / l\end{array}$ & $\begin{array}{l}\text { Se, } \\
\mu \mathrm{g} / \mathrm{l}\end{array}$ \\
\hline 7 days a.p. & $\mathrm{x}$ & $1133^{\mathrm{a}}$ & 172 \\
& SEM & 53.1 & 9.00 \\
calving day & $\mathrm{x}$ & 1020 & 174 \\
& $\mathrm{SEM}$ & 53.3 & 8.22 \\
7 days p.p. & $\mathrm{x}$ & 1041 & 181 \\
& SEM & 52.8 & 10.29 \\
14 days p.p. & $\mathrm{x}$ & $954^{\mathrm{a}}$ & 179 \\
& SEM & 55.9 & 6.44 \\
\hline
\end{tabular}

$x$ - mean value; SEM - standard error of means; significant differences between groups are indicated by using the same indices in a column: $a-P<0.05$

\section{Discussion}

\section{Negative energy balance - BCS values, NEFA and BHB concentrations}

Previous studies reported that higher BCS values $(>3.0, \geq 3.5)$ relate to NEFA concentrations in dairy cows and also showed a relationship between high BCS values and metabolic changes leading to increased incidence of oxidative stress and diseases in the periparturient period (Bernabucci et al., 2005; O'Boyle et al., 2006). Insufficient energy intake in the periparturient period results in a decrease in glucose levels and also in an increase in NEFA levels as a response to lipomobilization (Omur et al., 2016). In the present study a significant increase in NEFA concentration around calving in cows with the higher BCS (3.50 at the beginning of the experiment) was found. The changes in BCS value, respectively the decrease in BCS after parturition were not, however, significant $(P>0.05)$. There was not thus a significant loss of body condition in dairy cows as expected. This assumption may result in a significantly elevated but non-pathological NEFA 
concentration. A significant but non-pathological increase in NEFA concentration $(0.56 \pm 0.08 \mathrm{mmol} / \mathrm{l})$ in this study, as well as in our previous study by Píšt'ková et al. (2018), may be the reason for BHB concentration stability during the periparturient period and dairy cows not being predisposed to an increased incidence of ketosis. A slight increase in BHB concentration was also observed in the present study.

\section{Antioxidant status}

In dairy cows periparturient period is a critical phase which is extremely important to health, productivity and fertility (Roche et al., 2009). It is characterized by the depletion of antioxidants and results in an imbalance between pro-oxidants and antioxidants. The amount of antioxidants is insufficient to cope with the production of ROS and so oxidative stress occurs in dairy cows (Castillo et al., 2005).

\section{Glutathione redox state}

A decrease in GSH/GSSG ratio indicates ongoing oxidation processes (Dobbelaar et al., 2010). The GSH concentration may start to decline in consequence of peroxide reduction free radical scavenging (O'Boyle et al., 2006) and ROS reduction, as their quantity continues to increase in the periparturient period (Sordillo et al., 2007), while GSSG concentration increases.

In the present study the reduction in GSH concentration was reported from calving day to 14 days p.p., when there was again an increase in concentration. Findings of the present study are similar to Sordillo et al. (2007), who found the decrease in whole blood GSH concentration from prepartum to postpartum period ( $488 \pm 48 \mu \mathrm{mol} / 1$ on calving day and $341 \pm 19 \mu \mathrm{mol} / \mathrm{l}$ at 21 days p.p.) and to a study by Elischer et al. (2015), in which GSH concentration declined after parturition and the lowest value was recorded at 7 days p.p. $(226 \pm 13 \mu \mathrm{mol} / 1$ vs $288 \pm 14 \mu \mathrm{mol} / 1$ at 1 day p.p.). The significant increase in GSSG concentration after parturition in the present study was also in line with the findings of Sordillo et al. (2007), in which the highest GSSG concentration was observed on calving day (3.6 $\pm 0.7 \mu \mathrm{mol} / \mathrm{l})$. Elischer et al. (2015) reported the increased GSSG concentration after parturition in multiparous cows. Compared to GSH and GSSH concentration the differences in GSH/GSSG ratio were not, however, significant $(P>0.05)$. Data published in the previous studies (Sordillo et al., 2007; Elischer et al., 2015) are similar to findings observed in the present study, which showed a decrease in GSH/GSSG ratio in the postpartum period, especially at 7 days p.p. Moreover, between the GSSG concentration and the GSH/GSSG ratio a significantly negative correlation was found, which is in line with a study by Sordillo et al. (2007), who reported that the negative correlation indicates a shift in the redox potential of whole blood $(\mathrm{r}=-0.87$; $P<0.001)$.

In the study by O'Boyle et al. (2006), who recorded the change of GSH/GSSG ratio in relation to BCS in dairy cows, the GSH/GSSG ratio was $6.66 \pm 5.1$ in cows with normal BCS and $1.9 \pm 1.0$ in cows with high BCS. It seems that the cows with higher BCS are predisposed to a lower GSH/GSSG ratio compared to cows with normal $\mathrm{BCS}$. On the basis of this finding, we predicted the lower values of GSH/GSSG ratio and also a higher level of oxidative processes in dairy cows (BCS - 3.50) in the present study. This could partially confirm the findings of the present study showing a significantly positive correlation between the BCS value and the GSSG concentration. This is also supported by the results of GSH and GSSG concentrations, and GSH/GSSG ratio in the present study, which are in line with previously reported data for multiparous cows using the same GSH/GSSG-412 kit by OxisResearch (Sordillo et al., 2007; Elischer et al., 2015). Although the present study showed a decrease in the GSH/GSSG ratio, no significant correlation with BCS values was observed. The reason may be a not so significant decrease in BCS in the postpartum period, when the lowest BCS was recorded at 14 days p.p., which may indicate an attempt to cope with ROS and thus prevent a higher degree of oxidative processes.

\section{GPx activity}

In the case of GPx activity the depletion of antioxidant was recorded during the whole experiment. Compared to our previous study by Píšt'ková et al. (2018), in which the lowest GPx value was $793 \pm 269 \mu \mathrm{kat} / 1$ at 3 weeks p.p, a decrease in GPx activity in the present study was slower. Based on the findings, it could be associated with a lower BCS value before parturition (present study -3.50 and previous study -3.80 ) and confirm the fact mentioned above that cows with higher BCS are more susceptible to oxidative stress. As in the case of glutathione redox state, another possible explanation may be an insignificant change in $\mathrm{BCS}$ in the periparturient period in dairy cows and thus a lower level of ongoing oxidative processes. Adecrease of antioxidant activity around calving could 
result from depletion in the fight against ROS, which occur in higher concentrations in this period. The amount of antioxidants available is insufficient due to an ever increasing amount of ROS. O'Boyle et al. (2006) suggested that reduced antioxidant potential is more likely due to depleted antioxidant defense mechanism needed to reduce accumulated levels of ROS. As reported by Konvičná et al. (2015), decreased GPx activity is a reason for an increase in postpartal oxidative stress. The study by Cigliano et al. (2014), in which lower GPx and superoxide dismutase (SOD) activities were found in early lactating compared to mid-late lactating cows, reported that early lactation is related to a higher consumption of antioxidants because of the increased metabolic activity needed for milk production. Some researchers also suggested increased antioxidants activity as an effect of an increased risk of oxidative stress (Bernabucci et al., 2005; Dobbelaar et al., 2010).

\section{Selenium concentration}

Apart from determining GPx activity, selenium content was checked directly by checking selenium concentration in blood. Based on previous studies (Pilarczyk et al., 2012; Gong and Xiao, 2016) we expected a decreased Se concentration in the prepartum period due to the selenium transfer, necessary for the fetus, through the placental barrier. In the present study the lowest Se concentration was recorded at 7 days a.p., but was not significant compared to the other blood samplings. No significant changes in Se concentration were recorded from calving day until the last blood collection. A reason could be a sufficient concentration of selenium compared to reference values in cattle, so the concentration differences are not so prominent in dairy cows (Se whole blood concentration regarded as a reference value is $100-130 \mu \mathrm{g} / \mathrm{l}$ ) (Pilarczyk et al., 2012; Pavlata et al., 2001). This could be also the reason of the slower decrease in GPx activity as a seleniumdependent enzyme. Se concentration should also be decreased in peak lactation due to Se transfer from the blood to the milk produced at peak lactation. This could not be recorded because of the small time range of blood collections. The insufficient time range of prepartal blood sampling in the experiment may be also the reason for non-significant Se concentration differences compared to other groups.

\section{Conclusions}

Since the decrease in body condition score (BCS) was not so significant in the present study, the correlation between lower BCS and the evaluated non-esterified fatty acids (NEFA) concentration was also not significant. However, there is a presumption of correlation between BCS and NEFA concentration and its possible use as a suitable marker of energy balance. The results of the antioxidant/ oxidant parameters in the present study indicate that cows did undergo oxidative stress in the postpartum period. Decreased reduced glutathione (GSH) concentration and GSH/GSSG ratio and increased oxidized glutathione (GSSG) concentration after parturition support the contention that the glutathione redox status is an indicator of oxidative stress. It also seems that BCS correlates with these indicators and that its value before parturition and also loss of body condition postpartum could influence the level of oxidative processes in cows during the periparturient period. However, further studies are needed to clarify this issue.

\section{Acknowledgements}

This study was supported by grant IGA VFU Brno 115/2017/FVL and by the institutional research fund of the Faculty of Veterinary Medicine, University of Veterinary and Pharmaceutical Sciences Brno (Czech Republic).

\section{References}

Avanzo J.L., de Mendonça C.X., Pugine S.M.P., Cesar M.C., 2001. Effect of vitamin $E$ and selenium on resistance to oxidative stress in chicken superficial pectoralis muscle. Comp. Biochem. Physiol. C Toxicol. Pharmacol. 129, 163-173, https://doi.org/10.1016/S1532-0456(01)00197-1

Bernabucci U., Ronchi B., Lacetera N., Nardone A., 2005. Influence of body condition score on relationships between metabolic status and oxidative stress in periparturient dairy cows. J. Dairy Sci. 88, 2017-2026, https://doi.org/10.3168/jds.S00220302(05)72878-2

Cao L., Waldon D., Teffera Y., Roberts J., Wells M., Langley M., Zhao Z., 2013. Ratios of biliary glutathione disulfide (GSSG) to glutathione (GSH): a potential index to screen drug-induced hepatic oxidative stress in rats and mice. Anal. Bioanal. Chem. 405, 2635-2642, https://doi.org/10.1007/s00216-012-6661-8

Castillo C., Hernandez J., Bravo A., Lopez-Alonso M., Pereira V., Benedito J.L., 2005. Oxidative status during late pregnancy and early lactation in dairy cows. Vet. J. 169, 286-292, https:// doi.org/10.1016/j.tvjl.2004.02.001

Cigliano L., Strazzullo M., Rossetti C., Grazioli G., Auriemma G., Sarubbi F., lannuzzi C., lannuzzi L., Spagnuolo M.S., 2014. Characterization of blood redox status of early and mid-late lactating dairy cows. Czech J. Anim. Sci. 59, 170-181, https:// doi.org/10.17221/7341-CJAS

Dobbelaar P., Bouwstra R.J., Goselink R.M.A., Jorritsma R., van den Borne J.J.G.C., Jansen E.H.J.M., 2010. Effects of vitamin $E$ supplementation on and the association of body condition score with changes in peroxidative biomarkers and antioxidants around calving in dairy heifers. J. Dairy Sci. 93, 3103-3113, https://doi.org/10.3168/jds.2009-2677 
Elischer M.F., Sordillo L.M., Siegford J.M., Karcher E.L., 2015. Short communication: Characterizing metabolic and oxidant status of pastured dairy cows postpartum in an automatic milking system. J. Dairy Sci. 98, 7083-7089, https://doi.org/10.3168/ jds.2014-8941

Enkvetchakul B., Anthony N.B., Bottje W.G., 1995. Liver and blood glutathione in male broiler chickens, turkeys, and quall. Poult. Sci. 74, 885-889, https://doi.org/10.3382/ps.0740885

Esposito G., Irons P.C., Webb E.C., Chapwanya A., 2014. Interactions between negative energy balance, metabolit diseases, uterine health and immune response in transitiv dairy cows. Anim. Reprod. Sci. 144, 60-71, https://doi.org/10.1016/j. anireprosci.2013.11.007

Gong J., Xiao M., 2016. Selenium and antioxidant status in dairy cows at different stages of lactation. Biol. Trace Elem. Res. 171, 89-93, https://doi.org/10.1007/s12011-015-0513-2

Kaneko T., luchi Y., Kawachiya S., Fujii T., Saito H., Kurachi H., Fujii J., 2001. Alteration of glutathione reductase expression in the female reproductive organs during the estrous cycle. Biol. Reprod. 65, 1410-1416, https://doi.org/10.1095/ biolreprod65.5.1410

Konvičná J., Vargová M., Paulíková I., Kováč G., Kostecká Z., 2015. Oxidative stress and antioxidant status in dairy cows during prepartal and postpartal periods. Acta Vet. 84, 133-140, https://doi.org/10.2754/avb201584020133

Mayasari N., Chen J., Ferrari A., Bruckmaier R.M., Kemp B., Parmentier H.K., van Knegsel A.T.M., Trevisi E., 2016. Effects of dry period length and dietary energy source on inflammatory biomarkers and oxidative stress in dairy cows. J. Dairy Sci. 100, 4961-4975, https://doi.org/10.3168/jds.2016-11857

Meister A., 1983. Selective modification of glutathione metabolism. Science 220,472-477, https://doi.org/10.1126/science.6836290

Meister A., Anderson M.E., 1983. Glutathione. Ann. Rev. Biochem. 52, 711-760, https://doi.org/10.1146/annurev. bi.52.070183.003431

O'Boyle N., Corl C.M., Gandy J.C., Sordillo L.M., 2006. Relationship of body condition score and oxidant stress to tumor necrosis factor expression in dairy cattle. Vet. Immunol. Immunopathol. 113, 297-304, https://doi.org/10.1016/j.vetimm.2006.05.013

Omur A., Kirbas A., Aksu E., Kandemir F., Dorman E., Kaynar O., Ucar O., 2016. Effects of antioxidant vitamins (A, D, E) and trace elements $(\mathrm{Cu}, \mathrm{Mn}, \mathrm{Se}, \mathrm{Zn})$ on some metabolic and reproductive profiles in dairy cows during transition period. Pol. J. Vet. Sci. 19, 697-706, https://doi.org/10.1515/pjvs2016-0088

Paglia D.E., Valentine W.N., 1967. Studies on the quantitative and qualitative characterization of erythrocyte glutathione peroxidase. J. Lab. Clin. Med. 70, 158-169
Pavlata L., Pechová A., Bečvár O., Illek J., 2001. Selenium status in cattle at slaughter: analyses of blood, skeletal muscle, and liver. Acta Vet. Brno 70, 277-284, https://doi.org/10.2754/ avb200170030277

Pavlata L., Pechová A., Illek J., 2000. Direct and indirect assessment of selenium status in cattle - a comparison. Acta Vet. Brno 69, 281-287, https://doi.org/10.2754/avb200069040281

Pilarczyk B., Jankowiak D., Tomza-Marciniak A., Pilarczyk R., Sablik P. Drozd R., Tylkowska A., Skólmowska M., 2012. Selenium concentration and glutathione peroxidase (GSH-Px) activity in serum of cows at different stages of lactation. Biol. Trace Elem. Res. 147, 91-96, https://doi.org/10.1007/s12011-0119271-y

Píštková K., Kazatelová Z., Procházková H., Danielová L., Illek J., 2018. Antioxidant status and concentration levels of malondialdehyde (MDA) in dairy cows during periparturient period. Hungar. Vet. J. 140, Suppl. 1, 312-319

Roche J.R., Friggens N.C., Kay J.K., Fisher M.W., Stafford K.J., Berry D.P., 2009. Invited review: Body condition score and its association with dairy cow productivity, health, and welfare. J. Dairy Sci. 92, 5769-5801, https://doi.org/10.3168/jds.20092431

Sordillo L.M., 2005. Factors affecting mammary gland immunity and mastitis susceptibility. Livest. Prod. Sci. 98, 89-99, https://doi. org/10.1016/j.livprodsci.2005.10.017

Sordillo L.M., Aitken S.L., 2009. Impact of oxidative stress on the health and immune function of dairy cattle. Vet. Immunol. Immunopathol. 128, 104-109, https://doi.org/10.1016/j. vetimm.2008.10.305

Sordillo L.M., O'Boyle N., Gandy J.C., Corl C.M., Hamilton E., 2007. Shifts in thioredoxin reductase activity and oxidant status in mononuclear cells obtained from transition dairy cattle. J. Dairy Sci. 90, 1186-1192, https://doi.org/10.3168/jds. S0022-0302(07)71605-3

Spears J.W., Weiss W.P., 2008. Role of antioxidant and trace elements in health and immunity of transition dairy cows. Vet. J. 176, 70-76, https://doi.org/10.1016/j.tvjl.2007.12.015

Tarin J.J., 1996. Potential effects of age-associated oxidative stress on mammalian oocytes/embryos. Mol. Hum. Reprod. 2, 717-724, https://doi.org/10.1093/molehr/2.10.717

Tarin J.J., Ten J., Vendrell F.J., Cano A., 1998. Dithiothreitol prevents age-associated decrease in oocyte/conceptus viability in vitro. Mol. Hum. Reprod. 13, 381-386, https://doi.org/10.1093/ humrep/13.2.381

Tietze F., 1969. Enzymatic method for quantitative determination of nanogram amounts of total and oxidized glutathione: applications to mammalian blood and other tissues. Anal. Biochem. 27, 502-522, https://doi.org/10.1016/00032697(69)90064-5 